\title{
Spatial overlap between the leafscale gulper shark and the black scabbardfish off Portugal
}

\author{
Nuno VeIGA ${ }^{\mathrm{a}}$, Teresa MourA and Ivone FIGUEIREDO \\ Divisão de Modelação e Gestão de Recursos da Pesca, Departamento de Mar e Recursos Marinhos, IPMA, Instituto Português \\ do Mar e da Atmosfera, Av. Brasília, 1449-006 Lisboa, Portugal
}

\author{
Received 21 January 2013; Accepted 5 December 2013
}

\begin{abstract}
Information about the spatial distribution of bycatch species and their spatial overlap with the target species is essential for fisheries management. The present study used fishery-dependent data (vessel monitoring systems, logbooks and official daily landings) to study the spatial distribution and overlap between black scabbardfish Aphanopus carbo and leafscale gulper shark Centrophorus squamosus taken by the longline fishery operating off mainland Portugal. The geostatistical method kriging was applied to estimate the distribution of the leafscale gulper shark in relation to black scabbardfish and thus assess the impact of the fishery on the leafscale gulper shark. Results indicate that in fishing grounds where the black scabbardfish is more abundant, the relative occurrence of deepwater sharks is reduced. These findings have implications for alternative management measures to be adopted in this particular fishery, particularly where it concerns the minimization of deepwater shark bycatch.
\end{abstract}

Keywords: Spatial distribution / Spatial overlap / Bycatch / Deep-sea fish / Centrophorus squamosus / Aphanopus carbo / Northeast Atlantic Ocean

\section{Introduction}

Little effort has yet been devoted to identifying spatial patterns of bycatch species in different fisheries (Lewison et al. 2009). However, such knowledge constitutes important information for management and to propose technical measures that could minimize the levels of their capture (Sims et al. 2008). This is particularly important for the conservation of those species that present low resilience to commercial exploitation, as is the case of elasmobranchs, recognized to be frequently caught as bycatch in many fisheries worldwide (Bonfil 1994; Castro et al. 1999; STECF 2002). Indeed, it is commonly accepted that an overexploited elasmobranch stock presents a low recovery rate that may take several decades to reach the original population levels (Pratt and Casey 1990; Simpfendorfer and Kyne 2009). To address this issue in the Northeast Atlantic, several restrictions have been imposed by the European Union (EU), particularly for deepwater sharks, whose landings have been prohibited since 2010 (Council Regulation (EC) No 1359/2008 for the list of species included in Annex I of Regulation (EC) No. 2347/2002). This regulation affects several fisheries, leading to an increase in Elasmobranch discards, most often without any record of the amount, which makes it difficult to monitor and assess their stock status.

The black scabbardfish (Aphanopus carbo, Lowe 1839) fishery conducted in waters off the Portuguese mainland is one

\footnotetext{
a Corresponding author: nuno.veiga@ipma.pt
}

of the fisheries affected by this management measure. This fishery started in the early 1980s and has a high economic and social importance, even at the local scale. A detailed description of this fishery was presented by Bordalo-Machado and Figueiredo (2009). In 2004, the fleet targeting black scabbardfish was composed of 15 small artisanal longliners, each operating in defined fishing grounds. A fishing trip is usually characterized by two distinct fishing operations: a newly baited longline gear is deployed (setting) and another longline gear previously set is recovered (hauling). The main bycatch species of this fishery are two deepwater sharks with worldwide distributions (Compagno et al. 2005; Figueiredo et al. 2005): the Portuguese dogfish, Centroscymnus coelolepis Bocage and Capello 1864 and the leafscale gulper shark, Centrophorus squamosus (Bonnaterre 1788). The capture levels of these two species in the black scabbardfish fishery between 2000 and 2004 based on official data were low, representing $2.8 \%$ in numbers of specimens (Bordalo-Machado et al. 2009). It is noteworthy that before the introduction of the EU management measures, and largely due to the market price of deepwater shark liver, some of the vessels of this fleet frequently made trips targeting deepwater sharks.

Geo-referenced information on marine species constitutes an important tool for modelling their spatial distribution by the use of regression models (Eastwood et al. 2003), geostatistical methods (Stelzenmüller et al. 2004) or combinations of both techniques (Pittman et al. 2007). Off mainland Portugal, the distributions of black scabbardfish and leafscale 
gulper shark and the degree of their spatial overlap are poorly known. Ideally, the assessment of the spatial distribution of the main species captured in this fishery and their spatial overlap should be based on fishery research surveys, but those are not conducted at such depths off Portugal mainland. Nevertheless, a proposal for a longline deepwater survey off mainland Portugal and in the Bay of Biscay has been prepared by the International Council for the Exploration of the Sea (ICES) Working Group on the North-East Atlantic Continental Slope Survey (WGNEACS) with the objective of designing standardized surveys that will allow the estimation of a relative index of abundance and other population indicators for the black scabbardfish, deepwater sharks and other species (ICES 2011).

When fishery independent information is not available, other data sources can be used to infer the distribution and abundance of a species. In the NE Atlantic, and particularly within ICES jurisdiction area, the main sources of spatial information available are logbooks and the vessel monitoring system (VMS). Logbooks and VMS spatial information differ in the detail of the geographical information: in logbooks fishing hauls by day are assigned to a statistical rectangle (ICES statistical areas) whereas VMS data gives geographical coordinates, which provide a finer spatial resolution (Gerritsen and Lordan 2011). In the latter, in addition to the geographical position of the vessel, the speed and the direction of the vessel are recorded at regular time intervals allowing criteria to be set, based on vessel's speed and position, to identify the spatial locations of fishing hauls. Combining the VMS information with other sources of information (on-board observations, daily landing records or logbooks) it is possible to allocate species catch values to the same fishing haul.

Data from the Portuguese longline fishery will be used here to study the spatial distribution of the catches of black scabbardfish and leafscale gulper shark with the objective of evaluating their spatial overlap, based on the proportion of the deepwater shark in relation to the catch value of black scabbardfish. The spatial distribution of the leafscale gulper shark proportion is modelled and the level of spatial overlap evaluated applying the geostatistical method kriging (Cressie 1993). Leafscale gulper shark was selected for this study because it is considered to have a shallower bathymetric distribution than the other main bycatch species, the Portuguese dogfish (Clarke et al. 2001), and is thus more likely to present a higher overlap with the black scabbardfish. This study is based on fishery data for the years 2004 and 2005. This time range was adopted because of the EU reduction on the Total Allowable Catch (TAC) from 2006 to 2009 and the landings ban since 2010 (Council Regulation (EC) No. 1359/2008 for the list of species included in Annex I of Regulation (EC) No. 2347/2002) on deepwater sharks. Both measures may have led to an increase in discards and/or misreporting in recent years.

\section{Material and methods}

\subsection{Data preparation}

Three sources of information were used: VMS, daily landings and official logbook data (Portuguese DGRM database).
The VMS data available was provided for eight longline vessels targeting the black scabbardfish during the year 2004 (349 fishing hauls) and for one vessel targeting deepwater sharks during 2005 (116 fishing hauls). The data available for these vessels consisted of Global Positioning System (GPS) positions and was retrieved from the surveillance and monitoring system that records the activity of fishing vessels (MONICAP). The resolution of the VMS data was $0.01^{\prime}=0.01 \mathrm{nmi} \approx 20 \mathrm{~m}$ and for the current analysis no aggregation of data was performed. VMS data was used to identify the geographical position of fishing hauls (hauling operation) for the eight vessels targeting black scabbardfish, using the software toolkit developed by Bordalo-Machado et al. (2007) and Bordalo-Machado and Figueiredo (2007). This software was specifically designed to identify the fishing hauls from Portuguese deepwater longline fleet using this type of information. Since discards were negligible in this fishery (Bordalo-Machado et al. 2009) and each fishing trip hauling operation is followed by the respective landing of the catch at the fishing harbour, daily landings were used to allocate the catch of black scabbardfish and of leafscale gulper shark to the respective fishing haul. Note that, for all those vessels, the official daily landings were available for the same time period.

For the vessel whose activity was mainly directed to the capture of deepwater sharks (this vessel will be hereafter referred to as V1), VMS data was not available for the period before 2005. Given the difference the data time ranges between V1 and the former group of vessels, the consistency in the fishing activity of V1 between 2004 and 2005 was verified. Catch values of black scabbardfish and leafscale gulper shark recorded at daily landings along the two years were compared through boxplots and a $t$-Student test (level of significance of $10 \%$ ). Differences in the fishing grounds visited by V1 between years were also evaluated by calculating the relative frequency of occurrence of fishing hauls by ICES rectangle.

Vessel V1 presented a different fishing activity, which included trips with longer duration and two fishing operations per day, making the toolkit used for the first group of vessels inappropriate for identifying V1 fishing hauls. Thus, it was necessary to develop a new method to identify the V1 fishing hauls. Based on the information provided by the skipper of V1, it was assumed that one fishing haul corresponded to two hauling operations deployed close to each other (at a maximum distance of 2 nautical miles). The fishing haul locations were estimated as the midpoint of the GPS coordinates under the following assumptions: (i) the vessel speed during the hauling operation varied between 0 to 1 knot and (ii) the mean duration of the two hauling operations was about $10 \mathrm{~h}$. Furthermore, since more than one fishing haul was performed in each trip, daily landings could not be allocated to a particular fishing haul (it reports the total landed at a trip level). Logbooks were used instead since fishermen are required to fill them out with records of the total catch weight for each species by day of capture, ICES rectangle and gear.

To evaluate the relative importance in weight of the leafscale gulper shark and of the black scabbardfish, the proportion of the deepwater shark was calculated for each of the nine vessels. At each fishing haul, the proportion was estimated as the quotient between the landed weight of the leafscale gulper 
Table 1. Relative frequencies of the number of fishing hauls by ICES rectangle and by longliner vessel (Aphanopus carbo fleet) in 2004.

\begin{tabular}{ccccccccc}
\hline \multirow{2}{*}{$\begin{array}{c}\text { ICES } \\
\text { rectangle }\end{array}$} & \multicolumn{7}{c}{ Vessels } \\
\cline { 2 - 8 } & V2 & V3 & V4 & V5 & V6 & V7 & V8 & V9 \\
\hline 05E0 & & 0.79 & 0.93 & & 0.42 & & \\
06E0 & 1.00 & & 0.07 & & 0.06 & 1.00 & 0.01 \\
07D9 & & & & & 1.00 & & & 0.48 \\
07E0 & & & & & & & & 0.07 \\
08E0 & & & & & & & & 0.24 \\
09E0 & & & & & & 0.19 & & 0.20 \\
11E0 & & & & & & 0.33 & \\
Missing Data & 1.00 & & 0.21 & & & & \\
\hline
\end{tabular}

shark and the sum of the landed weight of black scabbardfish and of leafscale gulper shark. This proportion varies from 0 (when the leafscale gulper shark was not caught) to 1 (when no black scabbardfish was caught).

\subsection{Exploratory data analysis}

A preliminary exploratory analysis was performed to investigate the variability of the proportions by vessel and to identify variables (quarter, vessel and number of hooks) that partially explain the total variance of the observed proportions. The influence of quarter was evaluated through boxplots for V1 and for the remaining group of vessels separately. Since each longliner targeting black scabbardfish tends to have its own fishing ground (Table 1), the factors "fishing ground" and "fishing vessel" might be confounded. To circumvent this problem, a "group of vessels" factor was considered. The levels of this factor correspond to sets of vessels clustered according to their technical characteristics: engine power (in $\mathrm{kW}$ ), the gross tonnage, the vessel total length (in m) and the number of hooks. A hierarchical cluster analysis, implemented in the R software routine "hclust" from "stats" package (R Development Core Team 2012), was applied to identify the different groups. The clustering method adopted was the average method with the Malahanobis distance (which accounts for the covariance between variables).

\subsection{Spatial data analysis}

The spatial distribution of the leafscale gulper shark proportion was evaluated in Portuguese waters between latitudes of $38^{\circ} \mathrm{N}$ and $41^{\circ} \mathrm{N}$ (Fig. 1), which corresponds to latitude range of the deepwater longline fishery for the black scabbardfish (Bordalo-Machado and Figueiredo 2009). To have a first appraisal on the spatial distribution of the two species, the catch weight values as well as the proportion of leafscale gulper shark at each fishing haul were mapped using the $\mathrm{R}$ package "gstat" (Pebesma 2004).

The proportion values were considered to be realizations of a random function $Z(s)$ at fishing haul locations $(s)$. It was also assumed that $Z(s)$ was a stationary process, i.e., the spatial correlation between two fishing hauls $i, j$ made at different hauling locations $\left(s_{i}, s_{j}\right)$ depends only on their distance

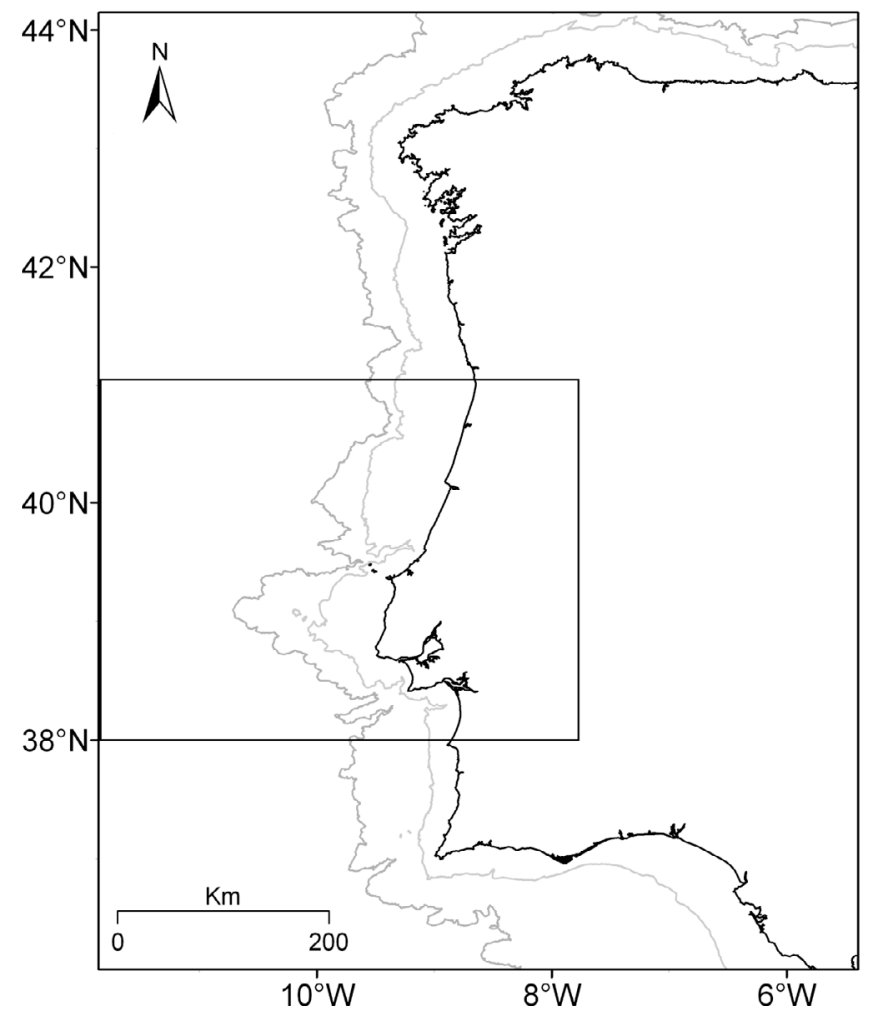

Fig. 1. Portuguese continental slope with bathymetric lines of $200 \mathrm{~m}$ (lighter) and $2000 \mathrm{~m}$ (darker). The area under study between $38^{\circ} \mathrm{N}$ and $41^{\circ} \mathrm{N}$ is marked by the rectangle.

$h=\left(s_{i}-s_{j}\right)$ (Bivand et al. 2008). Therefore, the spatial correlation between fishing hauls spatially separated by a distance $(h)$ was evaluated by the variogram function $2(\gamma(h))$ :

$$
2(\gamma(h))=\operatorname{Var}(Z(s)-Z(s+h)) .
$$

Several parametric variograms have been proposed to represent different patterns of spatial correlation (Cressie 1993). Variograms are parameterized in terms of: nugget effect, which reflects the variation at scales smaller than the sampling distances; partial sill, which corresponds to the vertical extent of the variogram representing the variance of the process; and range, which corresponds to the horizontal extent and reflects the distance at which the data are no longer autocorrelated (Bivand et al. 2008). The variogram parameters are estimated through the adjustment of a parametric semivariogram (half of the variogram) to the sample semivariogram $\hat{\gamma}\left(\bar{h}_{j}\right)$, which is based on the observed proportion values $Z\left(s_{i}\right)$ :

$$
\hat{\gamma}\left(\bar{h}_{j}\right)=\frac{1}{2\left|N_{h}\right|} \sum_{i=1}^{N_{h}}\left(Z\left(s_{i}\right)-Z\left(s_{i}+h\right)\right)^{2}, \quad \forall h \in \bar{h}_{j}
$$

where $N_{h}$ corresponds to the number of fishing haul pairs whose distance is $h$ and $\left|N_{h}\right|$ is the cardinality, i.e., the number of elements of $N_{h}$ (Cressie 1993). Spatial predictions of leafscale gulper shark proportion for locations other than those available in the data were performed using two kriging methods: ordinary kriging, which considers that the mean do not vary spatially, and universal kriging, in which the mean may 
a)

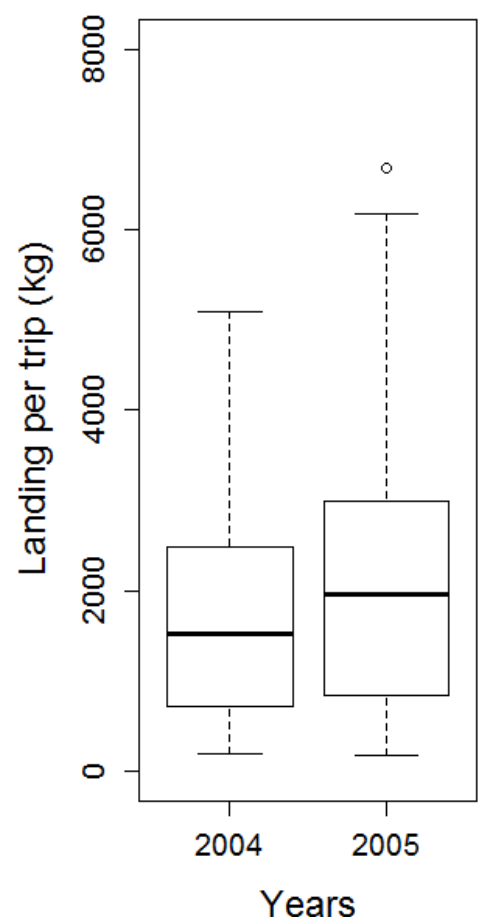

b)

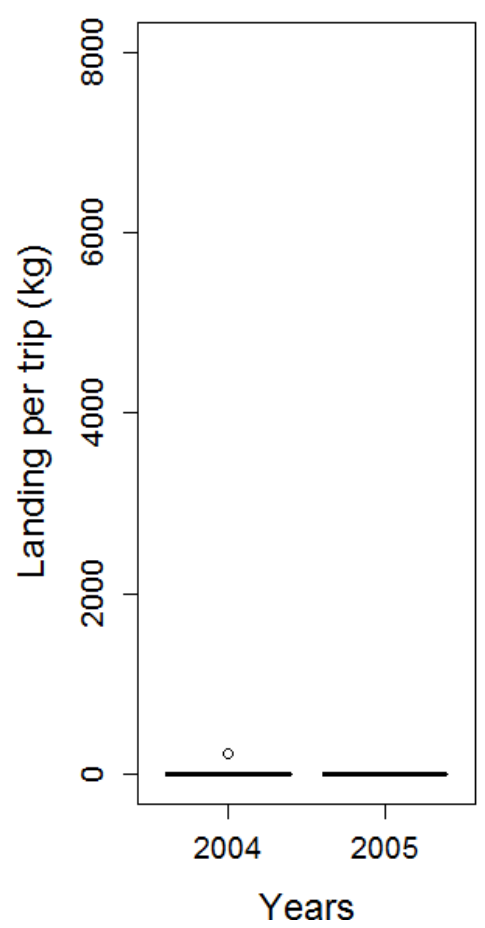

Fig. 2. Boxplots of the daily landing catch values (in kg) of (a) leafscale gulper shark and of (b) black scabbardfish from V1 in 2004 and 2005.

vary at different locations. The group of vessels factor was used as a spatial regressor.

In both methods, the error term was considered a random process with a zero-mean and a spatial correlation described by the parametric variogram. Several parametric variograms, e.g. exponential, spherical and Gaussian, were adjusted to the data using package "gstat" from R software (Pebesma 2004). A comparative graphical analysis of the empirical semivariogram with the different parametric semivariograms was performed to select the parametric semivariogram that better fitted the data. Residual error analysis and cross validation procedure were used to evaluate the adequacy of the selected model. Cross validation analysis involves splitting the data into two sets: the modelling and the validation set. The variogram model is adjusted to the first set and based on this; predictions are done for the locations of the validation set. The resulting kriging predictions are then compared with the observed values by calculating the z-scores, which are standardized residuals that include the kriging variance (Bivand et al. 2008).

\subsection{Spatial overlap}

The spatial overlap was graphically evaluated by mapping the kriging prediction of the proportion values obtained for a regular grid defined to include the points between $200 \mathrm{~m}$ and $2000 \mathrm{~m}$ depth, within latitude and longitude ranging between $38^{\circ} \mathrm{N}$ and $41^{\circ} \mathrm{N}$ and $7^{\circ} \mathrm{W}$ and $11^{\circ} \mathrm{W}$, respectively.

To estimate the level of spatial overlap between the target species (black scabbardfish) and the bycatch species (leafscale gulper shark), the observed proportion values at each fishing haul were grouped into three intervals according to their value.
Low level of spatial overlap corresponded to proportions of leafscale gulper shark in the catches close to 0 (no leafscale gulper shark) or close to 1 (all catch consisting of the leafscale gulper shark, i.e. no black scabbardfish). Ten predictions were determined for four different neighbourhood points located $100 \mathrm{~m}$ from each observed fishing haul using a sequential simulation algorithm that follows a random path method (for more details see Bivand et al. 2008). Histograms of the mean estimates for each interval were plotted and descriptive statistics were used to evaluate the spatial overlap between the two species.

\section{Results}

\subsection{Data preparation}

For the V1, both in 2004 and in 2005, landings were only made of the leafscale gulper shark, with only one exception where about $250 \mathrm{~kg}$ of black scabbardfish was caught (Fig. 2). Daily landings of leafscale gulper shark did not greatly differ between the two years since the null hypothesis of the mean of leafscale gulper sharks landings being equal was not rejected $(p \approx 0.22)$. Also, although with different frequencies, almost the same ICES rectangles were visited by V1 in the two years (Table 2), which was corroborated by the skipper, who indicated that the fishing grounds did not change between the two years. The analysis proceeded by assuming that the fishing activity and spatial area covered by V1 in 2004 and 2005 were similar, and consequently, the use of 2005 data in the analysis would not bias the conclusions 
Table 2. Relative frequency of the number trips made by V1 mainly directed to the capture of deepwater sharks in 2004 and 2005, by ICES rectangle.

\begin{tabular}{lcc}
\hline $\begin{array}{l}\text { ICES } \\
\text { rectangle }\end{array}$ & 2004 & 2005 \\
\hline $05 \mathrm{E} 0$ & $12 \%$ & $5 \%$ \\
$06 \mathrm{D} 9$ & $13 \%$ & $18 \%$ \\
$06 \mathrm{E} 0$ & - & $10 \%$ \\
$07 \mathrm{D} 9$ & $26 \%$ & $8 \%$ \\
$07 \mathrm{E} 0$ & $1 \%$ & $10 \%$ \\
$08 \mathrm{D} 9$ & $1 \%$ & - \\
$08 \mathrm{E} 0$ & $5 \%$ & $1 \%$ \\
Total & $58 \%$ & $52 \%$ \\
\hline
\end{tabular}

Leafscale gulper shark

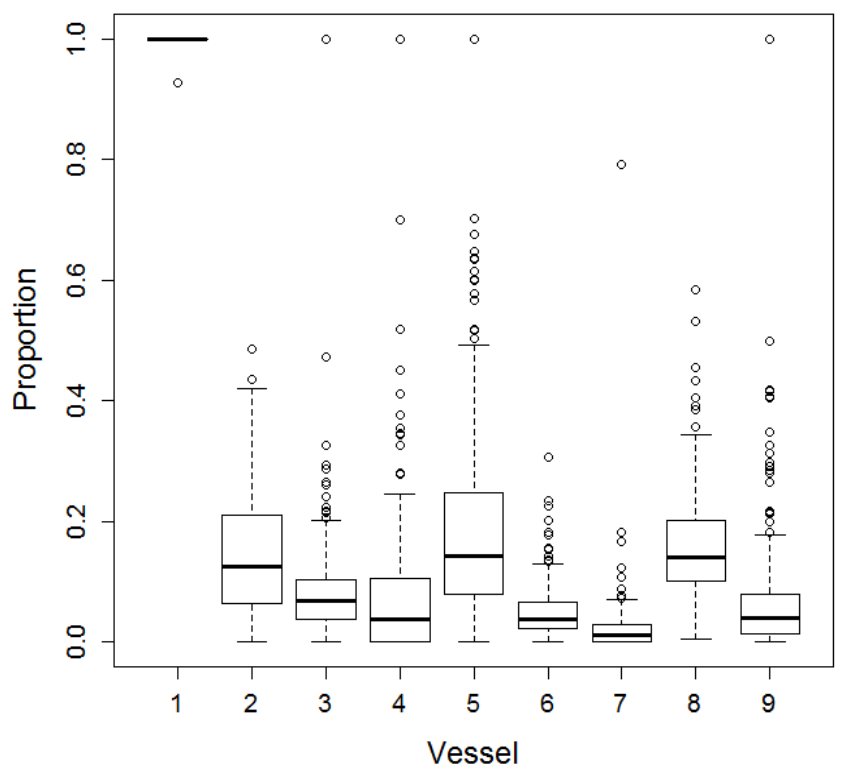

Fig. 3. Boxplot of the proportion of the landed weight of leafscale gulper shark in 2004 and 2005 (2060 fishing hauls).

\subsection{Exploratory data analysis}

Boxplots of the proportion of leafscale gulper shark by vessel for the period 2004-2005 shows that V1 clearly differs from all other vessels, by catching a high proportion of the leafscale gulper shark (Fig. 3).

For the whole set of vessels, no major differences were detected in the deepwater shark proportion between quarters (Fig. 4). V1 presented in all quarters a proportion of 1, while for the remaining vessels the median proportion was around 0.1 or less.

Four main subsets of vessels were identified as a result of the cluster analysis applied to vessel technical characteristics (Fig. 5). Group 1 and Group 2 are characterized by the lowest gross tonnage values and number of hooks, respectively. Group 3 is composed of the vessel with the high values for all the four factors under analysis and Group 4 is composed of the smaller sized vessels. This group of vessels variable, with four levels, will be later considered as a regressor variable in the universal kriging method.

\subsection{Spatial data analysis}

Spatial distribution of the raw landings values by species and by fishing haul shows geographical differences between the amounts caught of the leafscale gulper shark and of black scabbardfish (Fig. 6). The existence of spatial structure in the proportion is evident (Fig. 7): fishing hauls with high proportion values are distributed further from the coastline whereas those with lower values are located closer to the coast.

The best adjustments to the sample semivariogram were obtained with spherical function for the ordinary kriging (Fig. 8a) and with the exponential function for the universal kriging (Fig. 8c). The ordinary kriging results (Fig. 8b) were quite similar to those obtained with universal kriging method (Fig. 8d). However ordinary kriging gave the best cross validation results ( $z$-scores residuals should present a symmetrical distribution around zero and a variance close to 1) and the best residual distribution (symmetrically distributed around zero with no apparent structure) (Fig. 9), being the selected procedure in the following analysis.

The nugget effect, partial sill, and range estimates were 0 , 0.16 and 0.64 , respectively. The residuals analysis indicated that these did not present any structure; both the mean and the median estimates were $\approx 0$. The $z$-scores had a symmetrical distribution around 0 with interquartile range $\approx 1.5\left(q_{0.25}:-0.84\right.$; $\left.q_{0.75}: 0.67\right)$.

There were two areas of low predicted proportion values between $38.3^{\circ} \mathrm{N}$ and $39^{\circ} \mathrm{N}$ and $\approx 40^{\circ} \mathrm{N}$, at relatively shallow depths (considering the range adopted). Higher proportion values were predicted for three areas, $\approx 38^{\circ} \mathrm{N}, \approx 38.8^{\circ} \mathrm{N}$ and $\approx 39.5^{\circ} \mathrm{N}$, at deeper layers.

The ranges of the selected proportion intervals were: $[0,0.2[;[0.2,0.8]$ and $] 0.8,1]$ (Fig. 10a). The mean estimated proportion value of the predicted ordinary kriging simulations for fishing hauls included in the interval [0, 0.2[ was 0.07, which corresponds to a proportion of 0.02 in number (considering a mean individual body weight of leafscale gulper shark of $6.6 \mathrm{~kg}$ ). Nearly $95 \%$ of the predicted values were between 0 and 0.18 (Fig. 10b). For the interval [0.2, 0.8] the mean of the predicted proportion estimates was $\approx 0.3$ and $83 \%$ of the values were lower than 0.4 (Fig. 10c). For the interval ]0.8, 1], the mean was $\approx 1$ and $95 \%$ of the predicted values had a proportion value higher than 0.96 (Fig. 10d). In the latter interval, the average fraction in weight of black scabbardfish was around 0.004 .

\section{Discussion}

In the Portuguese deepwater longline fishery, the targeted black scabbardfish and the two deepwater sharks, Portuguese dogfish and leafscale gulper shark have historically been assessed based on fishery information. The difficulty in collecting samples and information on a regular basis creates problems for the abundance monitoring of the deepwater shark species and for knowledge of their dynamics, biology and ecology.

Before the adoption by the EU of restrictive measures on deepwater shark's landings, studies showed the importance of the two deepwater shark species in the Portuguese deepwater 
a)

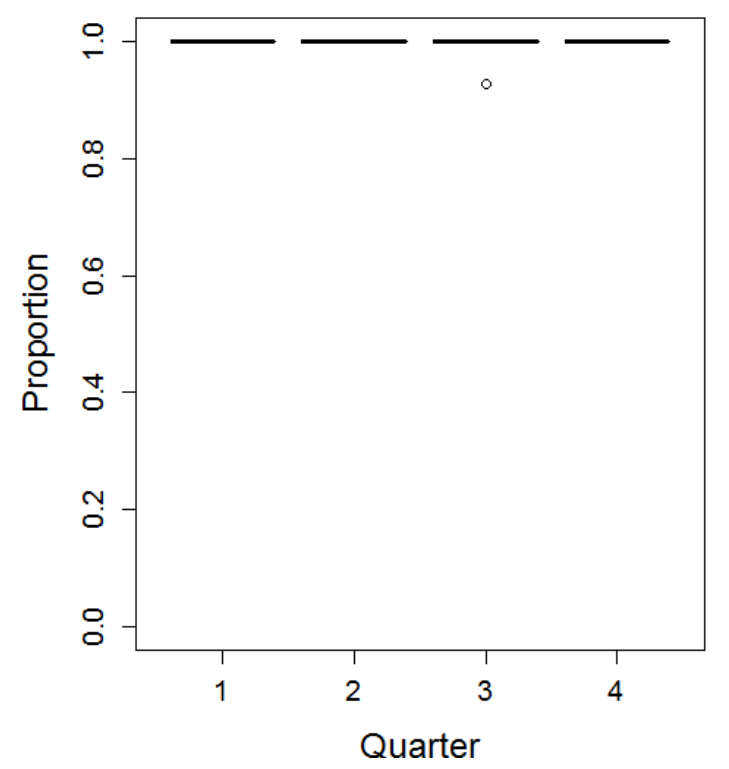

b)

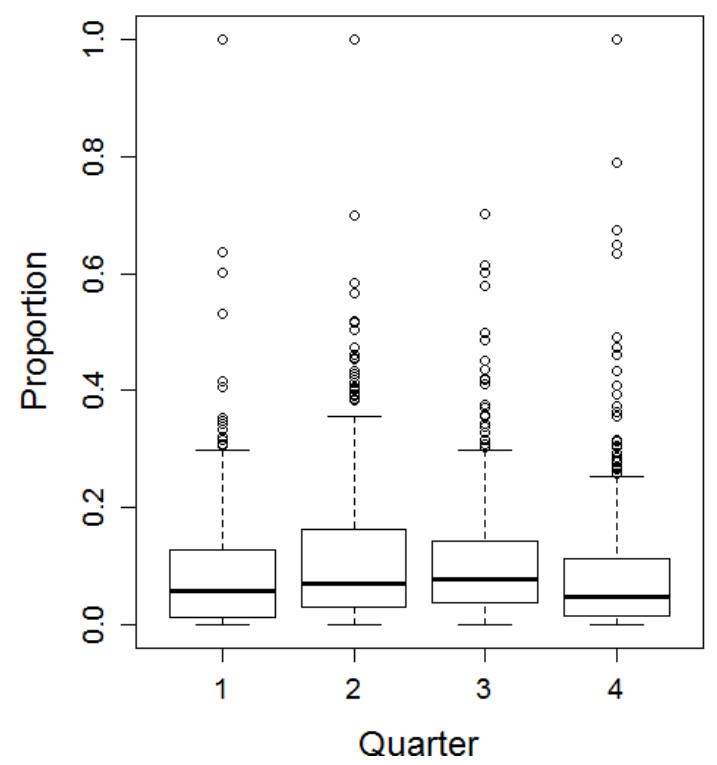

Fig. 4. Boxplot of leafscale gulper shark proportion values by quarter in 2004 and 2005 for (a) V1 and (b) V2-V9.

\section{Dendrogram}

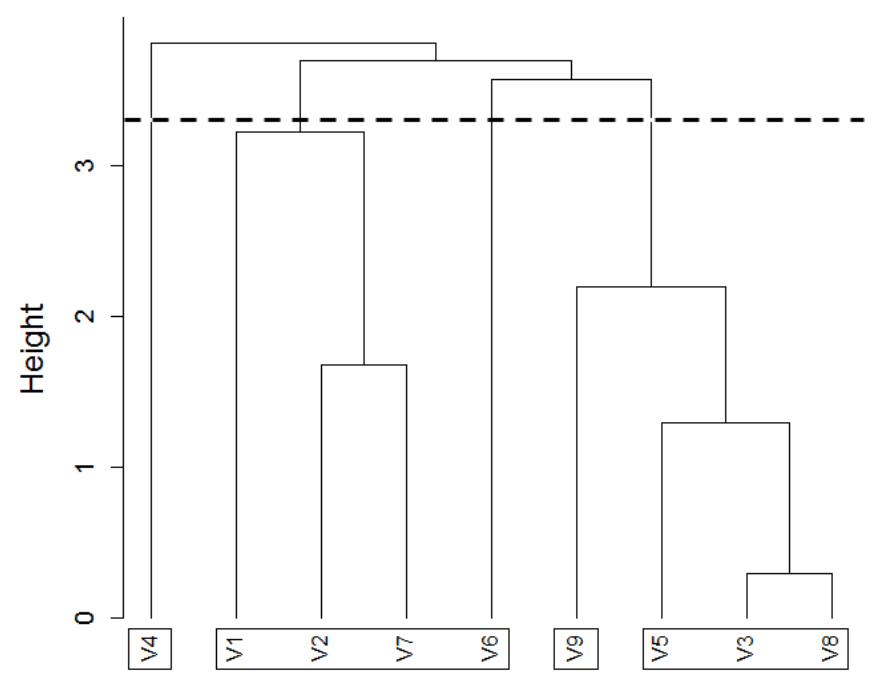

Vessel

Fig. 5. Hierarchical cluster analysis of vessel technical characteristics: engine power (in $\mathrm{kW}$ ), gross tonnage, total vessel length (in $\mathrm{m}$ ) and number of hooks. Four groups were identified (boxes) by the cutoff line (dashed line).

longline fishery (Figueiredo et al. 2005; Bordalo-Machado and Figueiredo 2009). These species represented $\approx 90 \%$ of the total bycatch in weight and $\approx 20 \%$ of the total income (BordaloMachado and Figueiredo 2009). Those studies also pointed out that the fishery was highly selective with the catches in number being almost exclusively composed by black scabbardfish and that the bycatch of deepwater sharks represented only $2.8 \%$ of the catch in number (Bordalo-Machado et al. 2009). Different figures have been estimated in other areas. In the Azores, deepwater sharks, all species combined represented $5 \%$ of the catch in number in longline fisheries (Machete et al. 2011). In the Canaries, leafscale gulper shark made up 6\% in number and $14 \%$ in weight of the total catch in surveys using the commercial fishing longline for black scabbardfish traditionally used in Madeira (Pajuelo et al. 2010). In this latter area, the proportion in number of leafscale gulper sharks was 0.13 , as calculated in the present study. However, catch composition in surveys carried out to sample a wide area may differ from commercial catches, which spatial distribution concentrates on the species of interest. In addition, it should be noted that, in both of these studies, the gears, hook sizes, depths of operation and deepwater shark species composition differ from the Portuguese mainland fishery. All these previous studies provided estimates of shark bycatch at the fishery level or for the area covered by a survey, but none evaluated the influence of the spatial distribution of the target species, i.e. black scabbardfish, and bycatch deepwater sharks species.

The current study integrated different sources of fishery information to evaluate the impact of the black scabbardfish longline fishery on the leafscale gulper shark, taking into consideration its different spatial distribution. There were some potential drawbacks, which resulted from relying on fisheries information only. After analysis, most of these drawbacks, e.g. data series available for different periods, were considered minor. Some other difficulties, which are not thought to impact the main results, must however be noted: the locations of fishing grounds are not randomly distributed over the whole study area and the assignment of the catch to the fishing location is not a straightforward procedure and rely on an additional data source. Furthermore, most vessels appeared to have their own fishing ground, which hampered the evaluation of a possible vessel effect on the catch composition. On the contrary, V1 had a different pattern in the distribution of its fishing effort, where it did not display the site fidelity of fishing operations but instead fished all along the Portuguese continental slope. 
a)

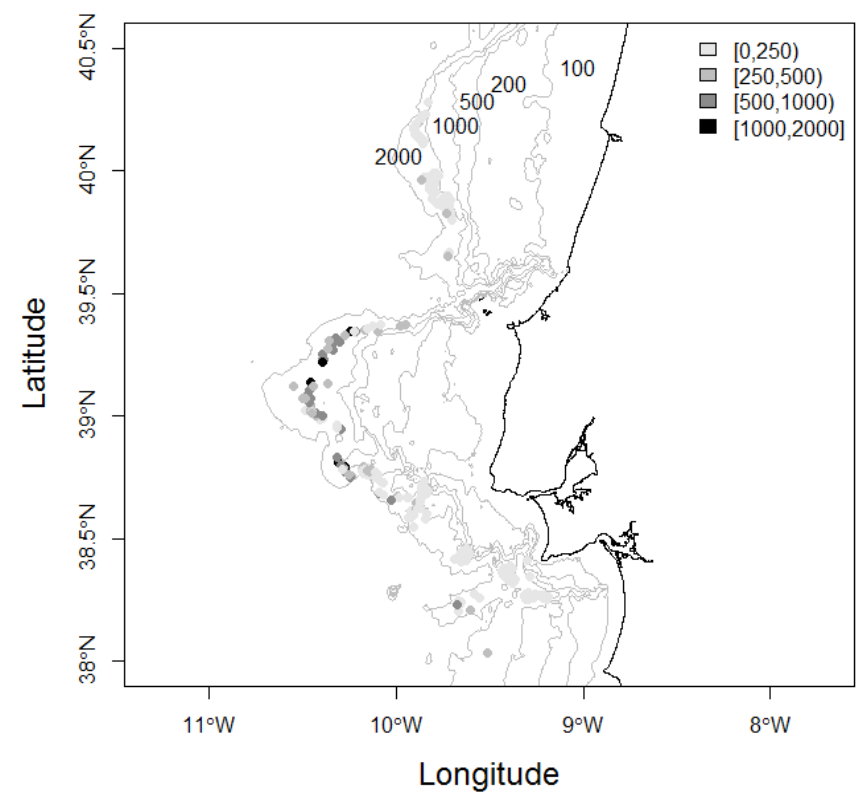

b)

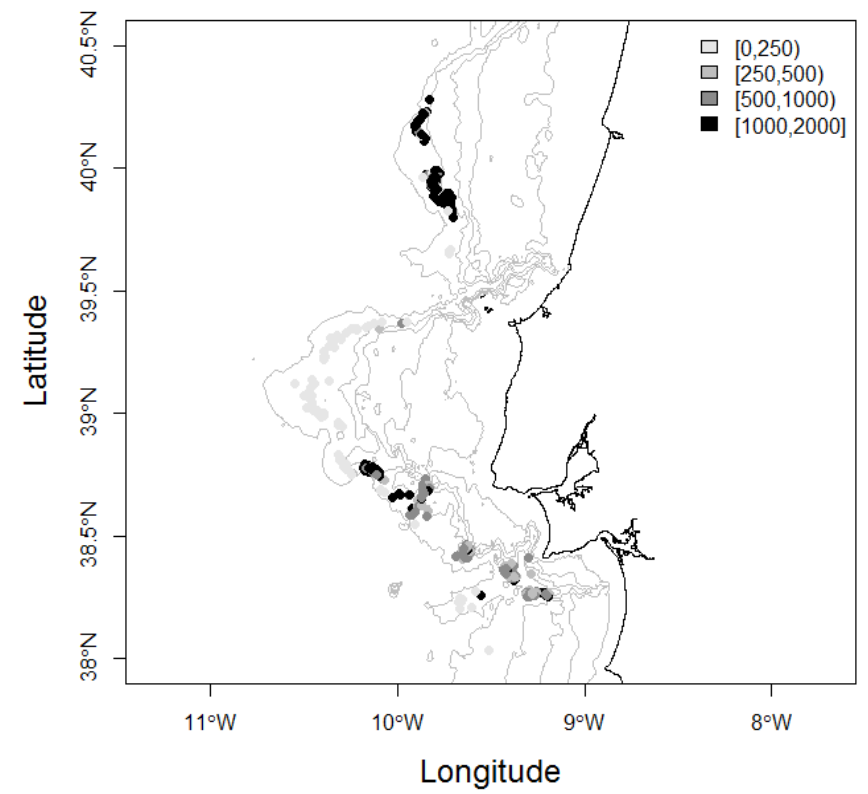

Fig. 6. Catch values (kg) by fishing haul and species (a) leafscale gulper shark and (b) black scabbardfish. Symbol colours represent different catch ranges. Isobaths are presented for $100 \mathrm{~m}, 200 \mathrm{~m}, 500$ $\mathrm{m}, 1000 \mathrm{~m}$ and $2000 \mathrm{~m}$.

These difficulties were circumvented by grouping vessels according to their technical characteristics and by restricting the data used for the latter vessel to a latitude range similar to that of other vessels included in the analysis. The resulting high spatial coverage of the fishing activity data provided by VMS data allowed using a geostatistical approach to evaluate the spatial distribution of the species. The interest of high resolution data for deepwater resource assessment and management was previously shown in some previous studies in the northeast Atlantic (Large et al. 2010; Augustin et al. 2013).

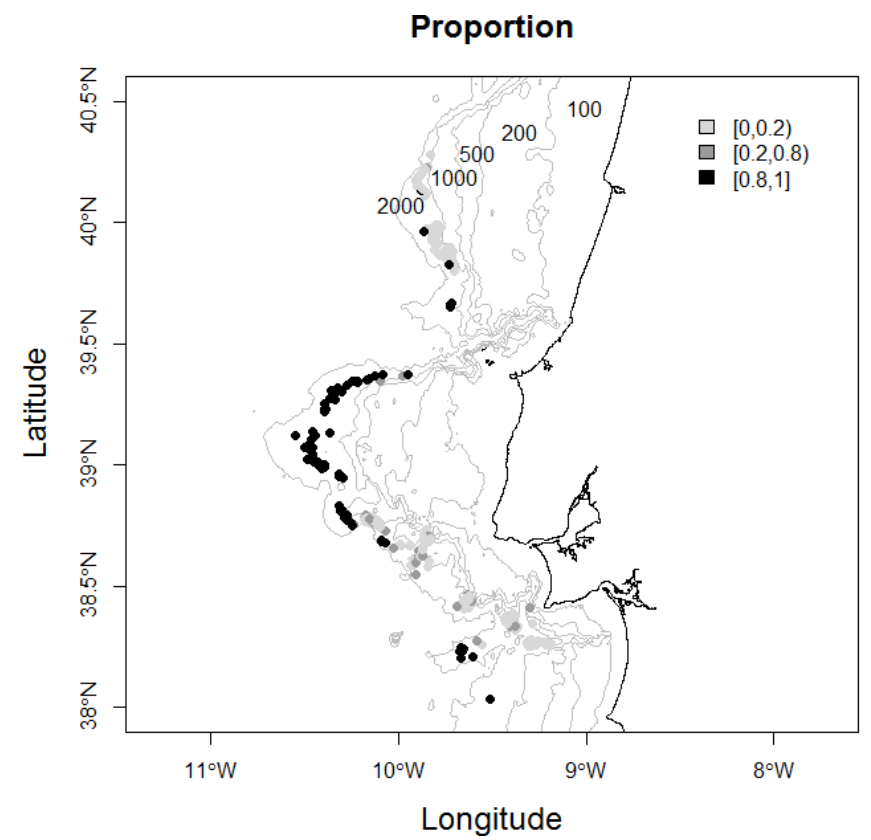

Fig. 7. Proportion of leafscale gulper shark by fishing haul location. Symbol colours represent different proportion ranges. Isobaths are presented for $100 \mathrm{~m}, 200 \mathrm{~m}, 500 \mathrm{~m}, 1000 \mathrm{~m}$ and $2000 \mathrm{~m}$.

The spatial overlap between the black scabbardfish and leafscale gulper shark was evaluated by using the proportion of the latter in black scabbardfish landings; this was considered adequate for getting insights on the spatial distribution of the deepwater shark irrespectively of differences in fishing capacities among vessels. A possible seasonal effect, hypothesized from the known seasonality in black scabbardfish catch per unit effort (ICES 2012), was investigated as a quarter effect and appeared not to affect the proportion of each deepwater shark. This may come from the seasonal variation in black scabbardfish catch being too small to have impact on the proportion; from concomitant variations in sharks catch rates; from much higher individual weights of deepwater shark than black scabbardfish; or from a combination of any of these factors.

Initially, the research on spatial overlap used methods integrating competition between species (Chase and Leibold 2003). More recently, research has been directed to elucidating how changing environmental conditions could affect species distributions (e.g., Etterson and Shaw 2001; Jump and Peñuelas 2005; Broennimann et al. 2007; Fitzpatrick et al. 2007; Steiner et al. 2008; Medley 2010). The methods adopted rely on either ordination techniques or species distribution models (SDM; Broennimann et al. 2012). The latter involves calibration (for each species) of statistical or machine-learning functions that relate environmental variables to georeferenced data on species occurrence (Guisan and Thuiller 2005). Examples of SDM methods are generalized linear models (McCullagh and Nelder 1989), maximum entropy (Philips et al. 2006), gradient boosting machine (Friedman 2001) and random forest (Breiman 2001).

Kriging methods have been used for modelling spatial distribution of species (Brodeur et al. 2008; Maxwell et al. 2009), making it possible to estimate continuous prediction surfaces and the error associated with the prediction. The lack 
a)

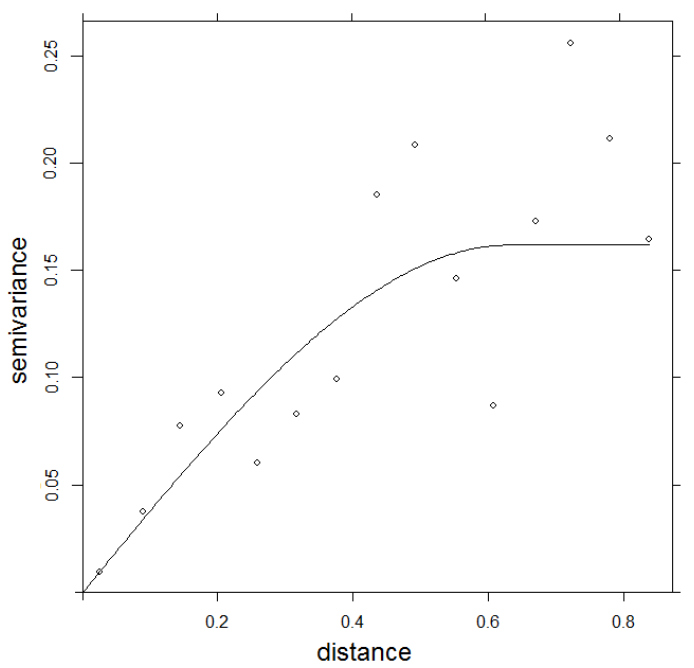

c)

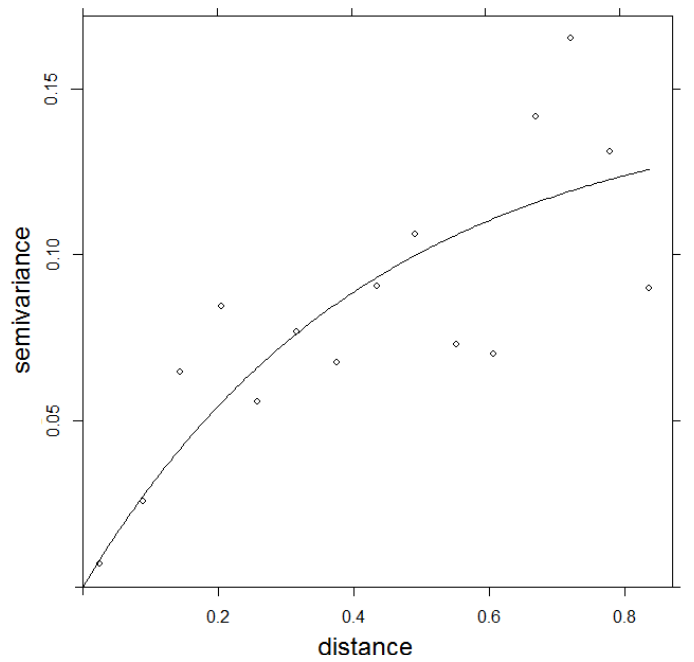

b)

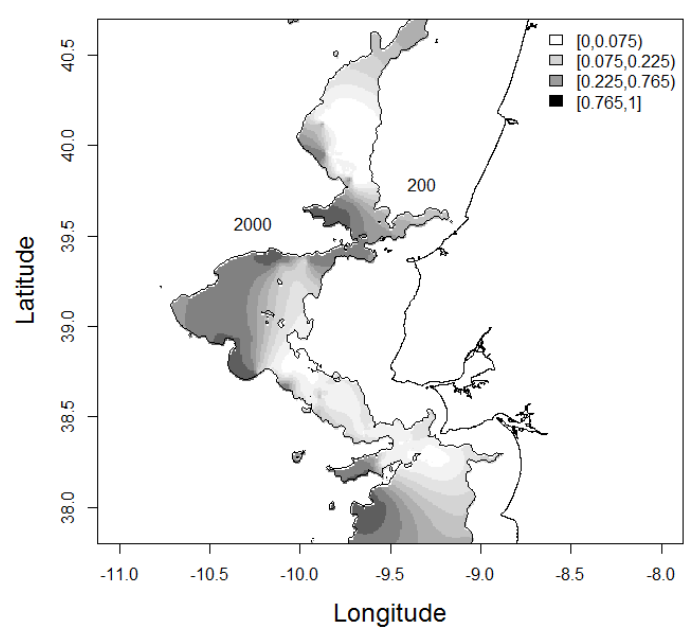

d)

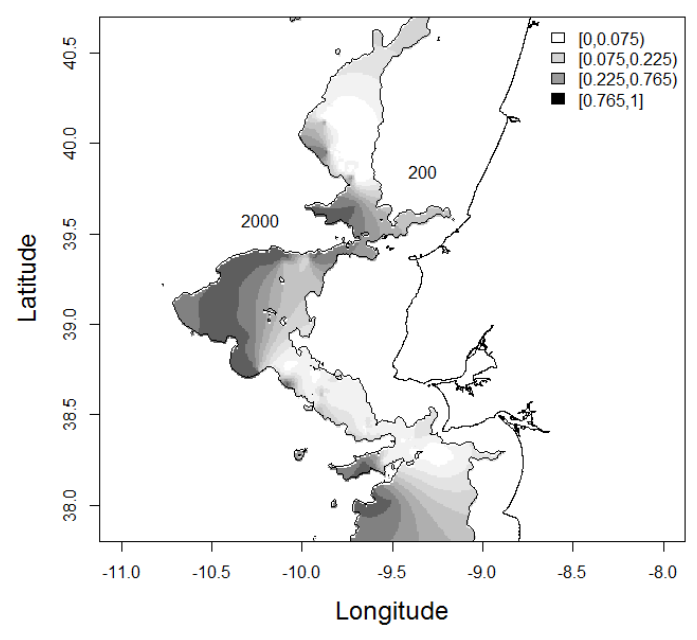

Fig. 8. Leafscale gulper shark proportion, (a) Sample variogram (points) and fitted spherical variogram (solid line), (b) Prediction results with ordinary kriging. (c) Sample variogram (points) and fitted exponential variogram (solid line), (d) Prediction results with universal kriging.

a)

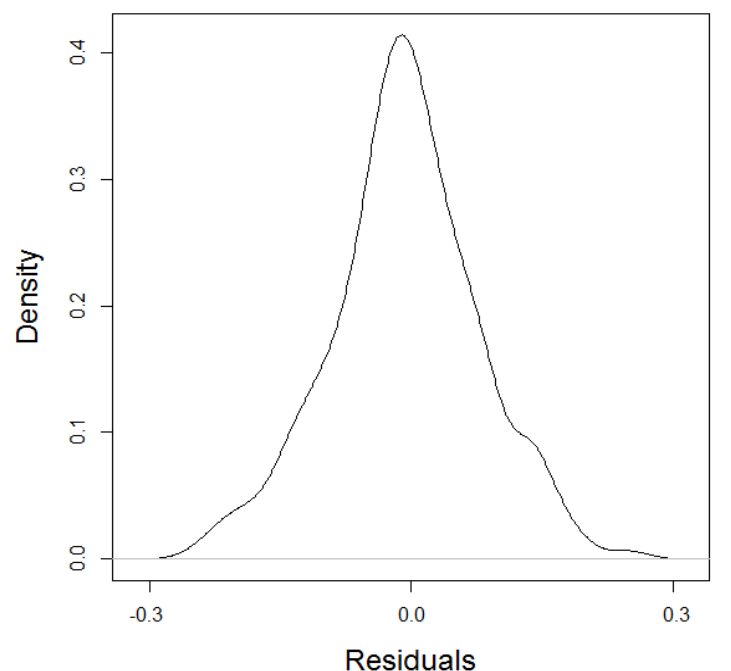

b)

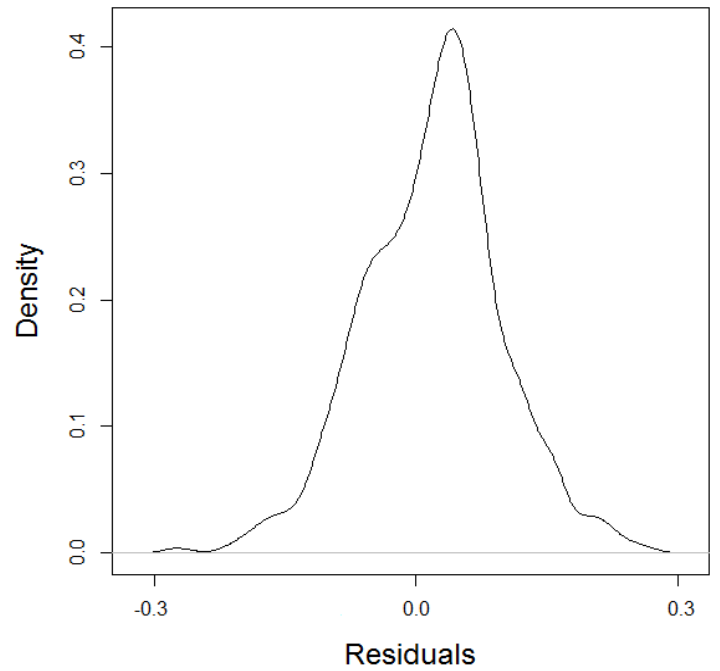

Fig. 9. Leafscale gulper shark density of (a) ordinary kriging residuals and (b) universal kriging residuals. 
a)

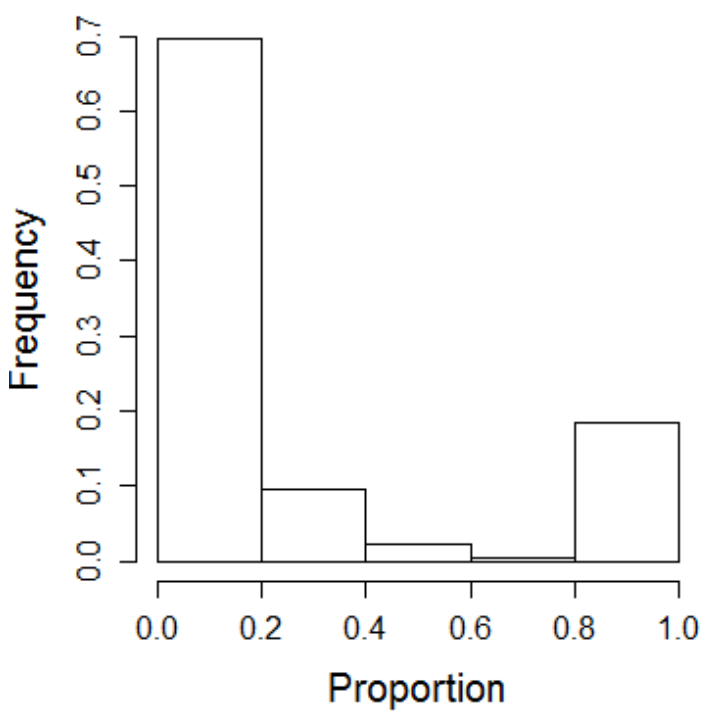

c)

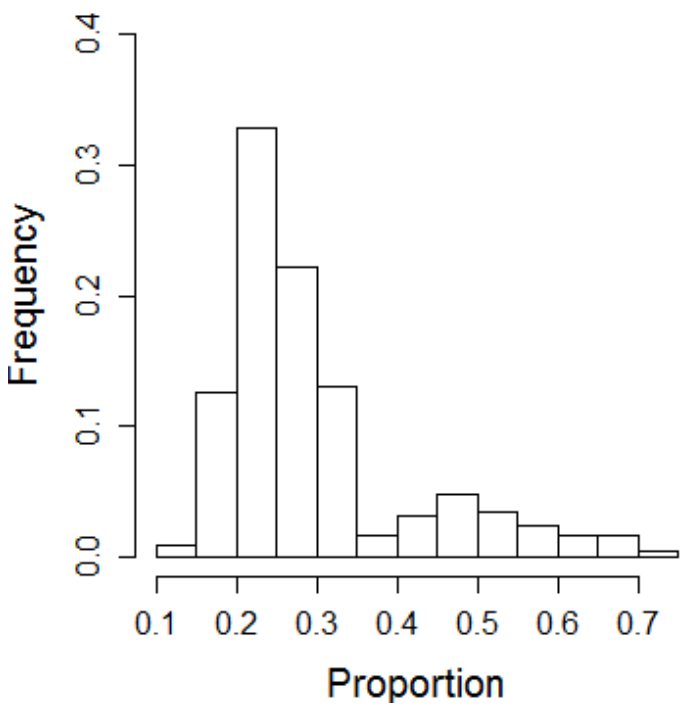

b)

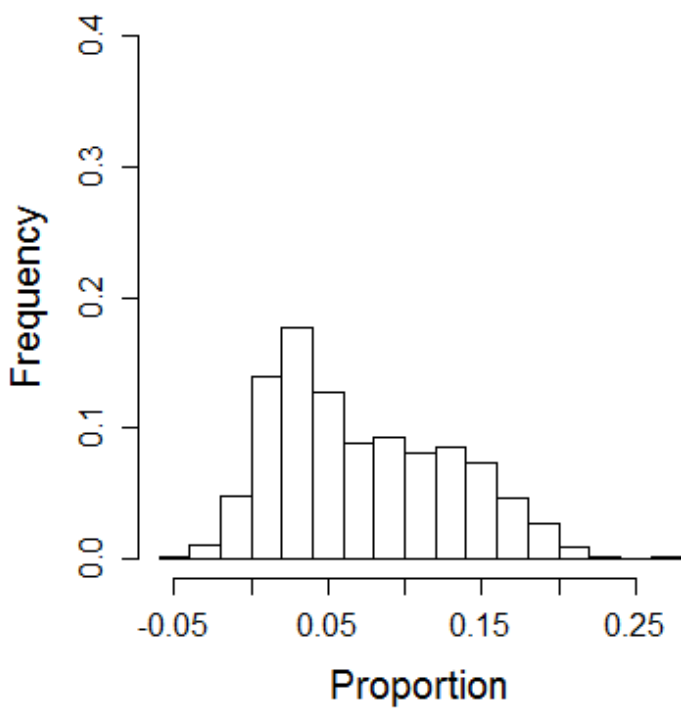

d)

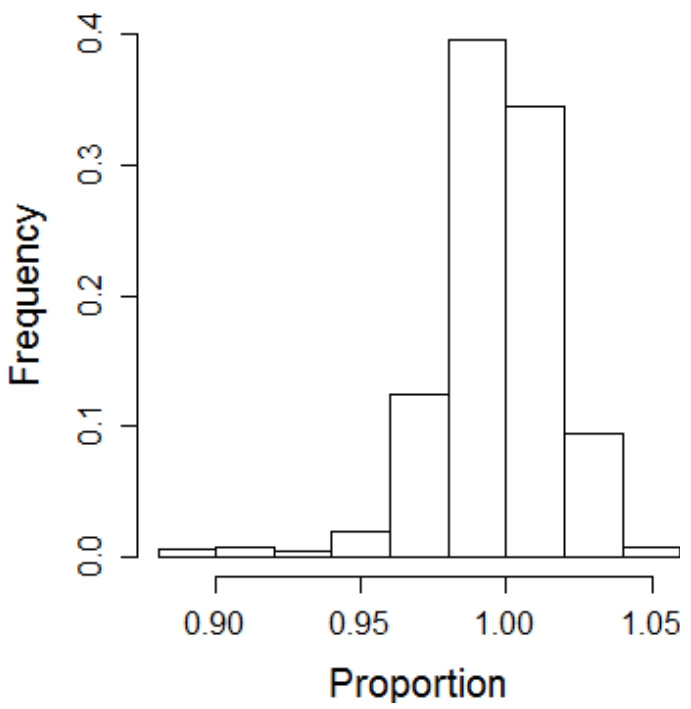

Fig. 10. (a) Histogram of the predicted leafscale gulper shark proportion estimates for ten kriging simulations at the spatial locations where observed proportion values belong to intervals (b) $[0,0.2[$; (c) $[0.2,0.8]$ and (d) $] 0.8,1]$.

of detailed information on environmental data within the area of the Portuguese deepwater longline fishery hinders the adoption of the techniques recently used to evaluate spatial overlap between species, which have been preferentially oriented to the quantification of the overlap of different environmental niches (Broennimann et al. 2012). In particular, depth data are missing for the Portuguese longline fishery because depth is not a mandatory field in logbooks, whose spatial resolution is at the level of ICES rectangle, each of these covering a wide depth range. However, depth might be a major factor for the evaluation of the abundance and proportion of leafscale gulper shark as well as black scabbardfish. In this respect, it is worth noting that the two species present different bathymetric ranges to the west of the British Isles, where the black scabbardfish is dominant between 600 and $1000 \mathrm{~m}$ (Bridger 1978; Ehrich 1983) and leafscale gulper shark have broader depth ranges, from 600 to $1500 \mathrm{~m}$ (more abundant at 1000-1100 m) (Clarke et al. 2001).

In the present study, the geostatistical analysis of high resolution data from numerous commercial fishing hauls showed that the leafscale gulper shark is not uniformly distributed in the study area. Results show that the spatial overlap between leafscale gulper shark and the black scabbardfish is low. Such a pattern can be detected either by the mapping of the proportion of leafscale gulper shark by fishing haul (the high frequency of proportion values close to 0 and to 1 ) or by the kriging estimates. It is further supported by the mean proportion estimates obtained for the kriging simulations at eachproportion 
interval adopted, with means $\approx 0.07$ and $\approx 1$. Even for the interval $[0.2,0.8[$ the predictions are skewed to the left, suggesting a low level of spatial overlap. In fact there are reports of high catch per unit effort (CPUE) values for leafscale gulper shark in some geographical areas off the British Isles where the CPUE values for the black scabbardfish are low (Kelly et al. 1997). Thus, the black scabbardfish fishery may operate at locations of lower abundance of leafscale gulper shark, which would then not be adversely impacted by this fishery although no survival is expected when this species is returned to the sea.

\section{Conclusion}

Results presented here indicate that the black scabbardfish fishery concentrates on fishing locations where the proportion of leafscale gulper shark in the catch is low. This is particularly valuable for the evaluation of the impact of the fishery on the populations of this bycatch species. Due to the generalized concern about deepwater sharks, it is extremely important that future studies include more species for which georeferenced data is available. The spatial distribution of these bycatch species will be valuable for conservation and for the management of deepwater sharks known to have particular life strategies, and generally accepted to have lower resilience to exploitation compared to other species (Garcia et al. 2008).

Acknowledgements. The authors would like to thank Pedro BordaloMachado, Pascal Lorance and two anonymous referees for their useful comments. The authors would also like to thank Cristina Silva (IPMA) for her help with maps. This study was partially supported by FP7-DEEPFISHMAN (Management and monitoring of deep-sea fisheries and stocks, Grant agreement No.: 227390), CERTIFICA (PROMAR 31-03-01-FEP-0032) and PNAB/DCF.

\section{References}

Augustin N.H., Trenkel V.M., Wood S.N., Lorance P., 2013, Space-time modelling for blue ling using soap film smoothers. Environmetrics 24, 109-119.

Bivand R.S., Pebesma E.J., Gómez-Rubio V., 2008, Applied spatial data analysis with R. New York, Springer.

Bonfil R., 1994, Overview of world elasmobranch fisheries. FAO Fisheries Technical Paper, Rome, No. 341.

Bordalo-Machado P., Fernandes A. C., Figueiredo I., Moura O., Reis S., Pestana G., Gordo L.S., 2009, The black scabbardfish (Aphanopus carbo, Lowe 1839) fisheries from Portuguese mainland and Madeira Island. Scient. Mar. 73, 63-76.

Bordalo-Machado P., Figueiredo I., 2007, Extraction and classification of longline fishing trips from vessel monitoring systems data with sequential recording gaps. 5th International Symposium, Spatial Data Quality 2007. Int. Soc. Photogram. Rem. Sens. Arch. $36-2 \mathrm{C} 43$

Bordalo-Machado P., Figueiredo I., 2009, The fishery for the black scabbardfish (Aphanopus carbo, Lowe 1839) in the Portuguese continental slope. Rev. Fish Biol. Fish. 19, 49-67.

Bordalo-Machado P., Sousa R.T., Matos J.G., 2007, A software toolkit to analyse vessel monitoring system data from longline fisheries. In: Nishida T., Kailola P.J., Caton A. (Eds.), GIS/Spatial analysis in fishery and aquatic sciences. Japan, Fishery-Aquatic GIS Research Group Saitama, Vol. 3, pp. 259-274.
Breiman L., 2001, Random forests, Machine Learnings 45, 5-32.

Bridger J.P., 1978, New deep-water trawling grounds to the west of Britain. Lowestoft, MAFF Directorate of Fisheries Research, Laboratory Leaflet No. 41.

Brodeur R.D., Suchman C.L., Reese D.C, Miller T.W., Daly E.A., 2008, Spatial overlap and trophic interactions between fish and large jellyfish in the Northern California Current. Mar. Biol. 154, 649-59.

Broennimann O., Treier U.A., Müller-Schärer H., Thuiller W., Peterson A.T., Guisan A., 2007, Evidence of climatic niche shift during biological invasion. Ecol. Lett. 10, 701-709.

Broennimann O., Fitzpatrick M.C., Pearman P.B., Petitpierre B., Pellissier L., Yoccoz N.G.,Thuiller W., Fortin M.-J., Randin C., Zimmermann N.E., Graham C.H., Guisan A., 2012, Measuring ecological niche overlap from occurrence and spatial environmental data. Glob. Ecol. Biogeogr. 21, 481-487.

Castro J.I., Woodley C.M., Brudek R.L., 1999, A preliminary evaluation of the status of shark species. FAO Fisheries Technical Papers, Rome, No. 380.

Chase J.M., Leibold M.A., 2003, Ecological niche: linking classical and contemporary approaches. The University of Chicago Press.

Clarke M.W., Connolly P.L., Bracken J.J., 2001, Aspects of reproduction of the deep-water sharks Centroscymnus coelolepis and Centrophorus squamosus from west of Ireland and Scotland. J. Mar. Biol. Assoc. UK 81, 1019-1029.

Compagno L., Dando M., Fowler S., 2005, Sharks of the World. London, Harper Collins Publishers, Collins Field Guide.

Cressie N., 1993, Statistics for Spatial Data. Revised edition, NewYork, Wiley. Wiley Series in Probability and Mathematical Statistics.

Ehrich S., 1983, On the ocurrence of some fish species at the slopes of the Rockall Trough. Arch. Fish. 33, 105-212.

Eastwood P.D., Meaden G.J., Carpentier A., Rogers S.I., 2003, Estimating limits to the spatial extent and suitability of sole (Solea solea) nursery grounds in the Dover Strait. J. Sea Res. 50, 151-165.

Etterson J.R., Shaw R.G., 2001, Constraint to adaptive evolution in response to global warming. Science 294, 151-154.

Figueiredo I., Machado P.B., Gordo L.S., 2005, Deep-water shark fisheries off the Portuguese continental coast. J. Northwest Atl. Fish. Sci. 35, 291-298.

Fitzpatrick M.C., Weltzin J.F., Sanders N.J., Dunn R.R., 2007, The biogeography of prediction error: why does the introduced range of the fire ant over-predict its native range? Global Ecol. Biogeogr. 16, 24-33.

Friedman J.H., 2001, Greedy function approximation: a gradient boosting machine. Ann. Stat. 29, 1189-1232.

Garcia V.B., Lucifora L.O., Myers R.A., 2008, The importance of habitat and life history to extinction risk in sharks, skates, rays and chimaeras. Proc. R. Soc. B 275, 83-89.

Gerritsen H., Lordan C., 2011, Integrating vessel monitoring systems (VMS) data with daily catch data from logbooks to explore the spatial distribution of catch and effort at high resolution. ICES J. Mar. Sci. 68, 245-252.

Guisan A., Thuiller W., 2005, Predicting species distribution: offering more than simple habitat models. Ecol. Lett. 8, 993-1009.

ICES, 2011, Report of the Working Group for North-east Atlantic Continental Slope Survey (WGNEACS), 14-16 June 2011, ICES HQ, Copenhagen, ICES CM 2011/SSGESST:15. 
ICES, 2012, Report of the Working Group on the Biology and Assessment of Deep-sea Fisheries Resources (WGDEEP), 28 March-5 April, Copenhagen, ICES CM 2012/ACOM:17.

Jump A.S., Peñuelas J., 2005, Running to stand still: adaptation and the response of plants to rapid climate change. Ecol. Lett. 8, $1010-1020$.

Kelly C.J., Clarke M., Connolly P.L., 1997, Catch and discards from a deep-water trawl survey in 1996. Fish. Leaf. 175, 1-16. Ir. Marine Institute, Dublin.

Large P.A., Diez G., Drewery J., Laurans M., Pilling G.M., Reid D.G., Reinert J., South A.B., Vinnichenko V.I., 2010, Spatial and temporal distribution of spawning aggregations of blue ling (Molva dypterygia) west and northwest of the British Isles. ICES J. Mar. Sci. 67, 494-501.

Lewison R.L., Soykan C.U., Franklin J., 2009, Mapping the bycatch seascape: multispecies and multi-scale spatial patterns of fisheries bycatch. Ecol. Appl. 19, 920-930.

Machete M., Morato T., Menezes G., 2011, Experimental fisheries for black scabbardfish (Aphanopus carbo) in the Azores, Northeast Atlantic. ICES J. Mar. Sci. 68, 302-308.

Maxwell D.L., Stelzenmuller V., Eastwood P.D., Rogers S.I., 2009, Modelling the spatial distribution of plaice (Pleuronectes platessa), sole (Solea solea) and thornback ray (Raja clavata) in UK waters for marine management and planning. J. Sea Res. 61, 258-267.

McCullagh P., Nedler J., 1989, Generalized linear models, 2nd edition. Boca Raton, FL, Chapman and Hall/CRC.

Medley K.A., 2010, Niche shifts during the global invasion of the Asian tiger mosquito, Aedes albopictus Skuse (Culicidae), revealed by reciprocal distribution models. Global Ecol. Biogeogr. $19,122-133$.

Pajuelo J.G., Gonzalez J.A., Santana J.I., 2010, Bycatch and incidental catch of the black scabbardfish (Aphanopus spp.) fishery off the Canary Islands. Fish. Res. 106, 448-453.

Pebesma E.J., 2004, Multivariable geostatistics in S: the gstat package. Comput. Geosci. 30, 683-691.
Philips S.J., Anderson R.P., Schapire R.E., 2006, Maximum entropy modeling of species geographic distributions. Ecol. Model. 190, 231-259.

Pittman S.J., Christensen J.D., Caldow C., Menza C., Monaco M.E., 2007, Predictive mapping of fish species richness across shallowwater seascapes in the Caribbean. Ecol. Model. 204, 9-21.

Pratt H.L, Casey J.G., 1990, Shark reproductive strategies as a limiting factor in directed fisheries, with a review of Holden's method of estimating growth parameters. In: Pratt Jr H.L., Gruber S.H., Taniuchi T. (Eds.). Elasmobranchs as living resources: advances in the biology, ecology, systematics and the status of the fisheries. NOAA Technical Report NMFS, No. 90, pp 97-109.

R Development Core Team, 2012, R: A language and environment for statistical computing. R Foundation for Statistical Computing, Vienna, Austria. ISBN 3-900051-07-0, URL http:// www.R-project.org/.

Simpfendorfer C.A., Kyne P.M., 2009, Limited potential to recover from overfishing raises concerns for deep-sea sharks, rays and chimaeras. Environ. Conserv. 36, 97-103.

Sims M., Cox T., Lewison R., 2008, Modelling spatial patterns in fisheries bycatch: improving bycatch maps to aid fisheries management. Ecol. Appl. 18, 649-661.

STECF, 2002, Report of the subgroup on resource status (SGRST) of the scientific, technical and economic committee for fisheries (STECF). Brussels elasmobranchs fisheries.

Steiner F.M., Schlick-Steiner B.C., VanDerWal J., Reuther K.D., Christian E., Stauffer C., Suarez A.V., Williams S.E., Crozier R.H., 2008, Combined modeling of distribution and niche in invasion biology: a case study of two invasive Tetramorium and species. Divers. Distrib. 14, 347-357.

Stelzenmüller V., Maynou F., Ehrich S., Zauke G.P., 2004, Spatial analysis of twaite shad, Alosa fallax (Lacepède 1803), in the Southern North Sea: application of non-linear geostatistics as a tool to search for special areas of conservation. Int. Rev. Hydrobiol. 89, 337-351. 